\section{The misunderstood geneticist}

\section{The Misunderstood Gene \\ By Michel Morange \\ Translated by Matthew Cobb}

Harvard University Press, \$24.95, ISBN 0-674-00336-5, 2001

Reviewed by Robert Pollack

Department of Biological Sciences, Columbia University, New York, New York, USA

Of all the misunderstandings that separate the practicing scientist from the rest of the world of curious people, none is more pervasive and more apt to trivialize the scientific enterprise than the general notion that scientists know secrets. Not true. Nothing valuable in science is a secret for long; science is the social enterprise that most resembles the beehive, and no idea, no discovery, no new data can possibly be both important to a field and secret from it. Yet somehow we find ourselves beset by the general presumption that a basic science laboratory is a place where secrets are kept, not revealed. This makes science threatening, and indeed many people are threatened today by the thought that laboratories are holding onto secrets concerning matters of personal import. Of these, none is more threatening to more people than the thought that a medical research laboratory somewhere may be secretly peeking at one's genes, or the notion that the tools of genetics and molecular biology have given research scientists the capacity to learn the secrets of human individuality, allowing them to use DNA data to worm their way into a person's very soul.

Some of this may indeed be happening, as corporations drive through the gap that has opened between legal notions of privacy and the newly merging technologies of web-based data collection and fast DNA sequencing, but you can be sure that the corporate peekers and the problems they engender are not aspects of basic science at all. Why this confusion between the necessarily public work of basic research and the private realities of corporate life?
There are many reasons for the persistence of this misplaced worry about basic research-certainly the power of patent lawyers to circumscribe new knowledge and repackage it as private property is a real threat to the freedom and openness of basic research - but beyond this and other economic reasons, there is the more interesting possibility that basic scientists themselves contribute to this mistake by failing to clearly articulate what they consider to be the larger social meanings of their work.

In The Misunderstood Gene, Michel Morange, professor of biology and director of the Center for the Study of the History of Science at the École Normale Supérieure in Paris, has pulled together a considerable amount of recent basic research in a noble but flawed attempt to lay out the distinctions among the many datadriven definitions of a 'gene,' and the surprising distance of all of these from the metaphor-driven meanings of this word in one or another non-scientific segment of society at large. Noble, because he writes from within the field and is clearly himself a liberal-minded person, not subject to the temptations of genetic determinism. The book uses an extraordinary number of examples of interesting work today in molecular biology, genetics and embryonic development to show how the gene is operationally defined within these fields.

Flawed, because he assumes too much of his lay readers. He has made some definitions of the gene unnecessarily difficult by failing to make clear a few of the distinctions that have had the most troubled history in the larger society, in particular the difference between a recessive and a dominant allele, and between the temporary immortality of a species' gene pool and the certain mortality of any individual in that species. This problem is an aspect of the larger issue of the author's chosen voice. $\mathrm{He}$ - or his translator-has not written in a single voice, but has rather allowed the level of detail and specificity to rise and fall without any apparent logic.

Here is one example, taken from the chapter that deals with knockout mice. The point he is making is that often knockout mice show little or no new phenotype, suggesting that molecular models of gene or protein function that are based on cellular or in vitro studies may be flawed in their inability to take into account the full interplay of all genes in all cells of a developing whole organism:

"The title of the article claimed that 'Mice devoid of the glial fibrillary acidic protein develop normally and are susceptible to scrapie prions.' The result, which was negative because it cast no light on the role of this type of intermediate filament, was given a positive spin by suggesting that astrocytes play no role in prion infections and that only neurons are involved in the development of such diseases. Unfortunately for the authors, recent studies show that in the absence of neurons, astrocytes can propagate the pathogenic form of the scrapie protein. These studies of intermediate filaments are striking and disturbing, but it is not clear what lessons can be drawn."

The long stretches of current science that are the best written are likely to be fully comprehensible only to the people who will not need this book to understand the work. The breezy commentary that separates these arid stretches is easily grasped by the lay reader, but as it is often so timid as to be fatuous, it tends only to confirm any suspicion already in place that scientists speak a hermetic tongue in order to keep their secrets to themselves. The result of many examples of tightly drawn science followed by flaccid reflection is a choppy book, best suited to a smaller audience than the author would wish to reach. But for that audience, it will provoke many new questions. 